\title{
Likeability and the double bind
}

Alison Williams

Be good, sweet maid,

and let who will be clever.

Charles Kingsley, Poems of Home:

IV.Youth A Farewell (1904).

Within academia, men are over-represented at professorial level. Although the focus of enquiry has, thankfully, moved beyond the argument: "Such a big book for such a little head" (Edna St Vincent Millais, 1941) and past Virginia Woolf's angry professors (1929), nevertheless, the ratio of women to men at senior levels remains stubbornly out of balance.

One barrier to equality is stereotypical views of women. This article draws on recipes and articles in this book and looks at the impact, prejudices and expectations that stereotypes create, particularly around likeability, and the behaviours that can result. It then suggests ways forward.

The idea that there is a 'right' way to be a woman, to perform one's gender, is ongoing and pervasive. Good women are modest, charming, polite and unobtrusive, content to earn, on average in the UK, $16.4 \%$ less than their male counterparts (see Salary negotiation), and to pick up the double load of career and house/child/elderly parent care. 'Good' women are liked. 'Bad' women are those who don't adhere to these standards (Gay, 2014, pp. 303-304), and by performing their gender 'wrong' initiate a set of punishments both obvious and indirect (Butler, 1988). 'Bad' women are disliked.

Stereotypes - fixed, oversimplified and widely held ideas about particular groups - have their origins in cognitive mechanisms, developed at a very young age, of early and primitive generalisations which deeply influence our 
judgements about members of a kind (Leslie, 2017). Fiske et al. (2002) shed light on the social and cultural complexity of stereotypes, proposing that they can be delineated on two axes: competence and warmth. Competence is aligned strongly with perceptions of another's status or power and hence their competitiveness for available resources; warmth is the extent to which the group is seen as warm, trustworthy and friendly.

Fiske et al. examine the emotions people hold in relation to the stereotypes, and the prejudices that ensue (Figure 1). In quadrant 1 (top right), with high competence and high warmth, all the group members have status and power, and at the same time do not perceive each other as competing for resources. In the context of this study they are part of the institutional in-group or close allies: 'one of us', as opposed to the meaning in psychology of 'my group, whatever it is' (Fiske, in correspondence with the author in 2017). Fiske's study participants (reflecting their US university student demographic) identified quadrant 1 members, among others, as 'whites', 'middle-class', 'Christians' and 'students'.

In quadrant 2 (top left), with low competence and high warmth, people are perceived as "subordinate and non-competitive" (p. 878) and therefore warm, friendly and trustworthy - i.e. 'good'. The study participants identified and included 'housewives', 'the disabled' and 'the elderly' in this cluster.

People placed in quadrant 3 (bottom right), with high competence and low warmth, are perceived as high competence, high status and powerful, competitive, exploitative and self-serving, therefore threatening. Study participants identified and included 'black professionals', 'feminists' and 'the rich' in this cluster.

In quadrant 4 (bottom left), group members are perceived as exploitative, low-status

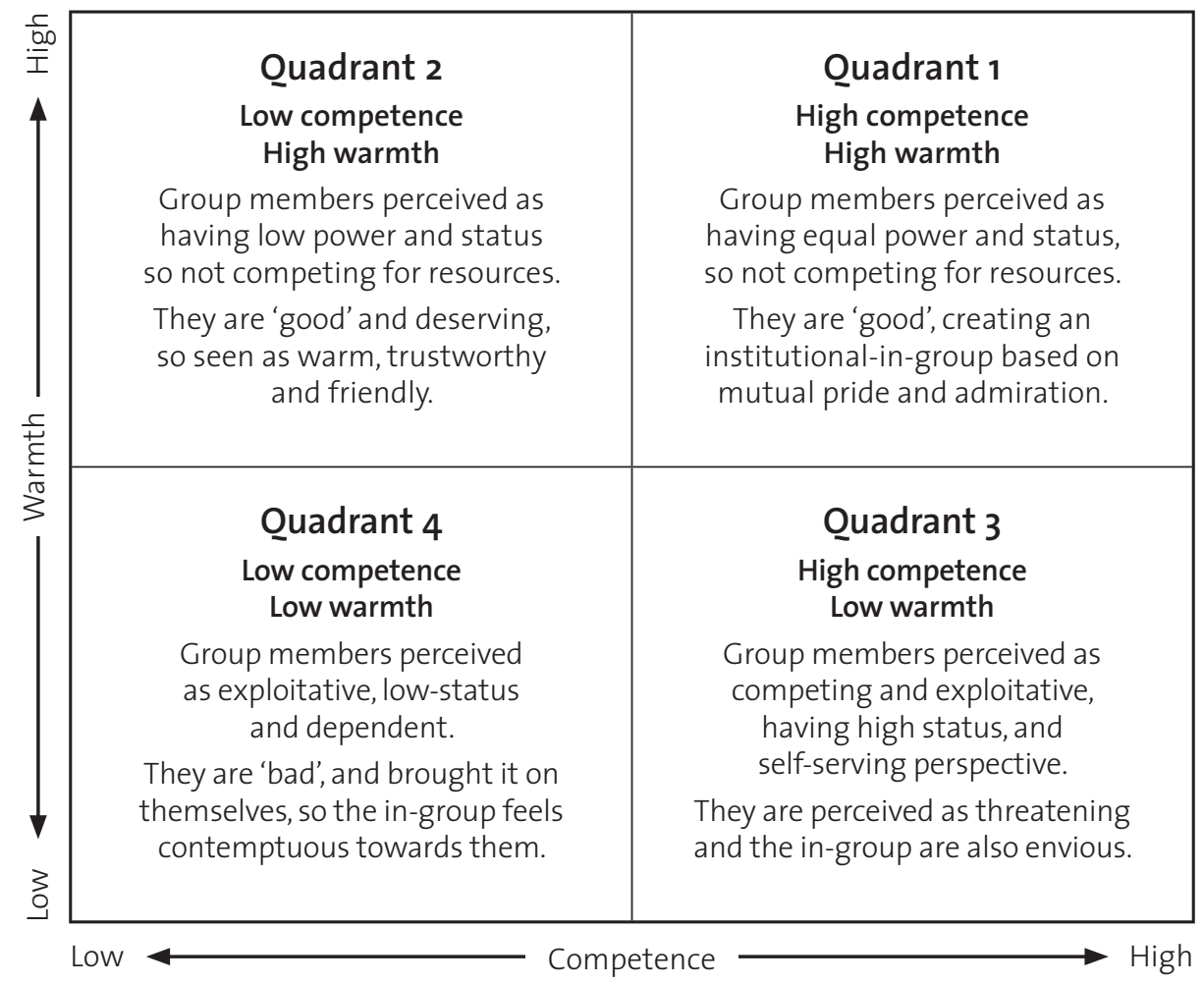

Figure 1: A model of stereotype content and prejudice (adapted with permission from Fiske et al 2002) 
and dependent. Study participants identified and included 'the homeless' and 'welfare recipients' in this quadrant.

The researchers then describe what they call prejudiced emotions arising in the four different quadrants.

Paternalistic prejudice is directed towards people placed in quadrant 2 (top left) eliciting sympathy and pity. Paternalistic power relations can show up as benevolent sexism, with traditional 'good' women home-makers - serving as the 'women are wonderful' default (Haddock \& Zanna, 1994). "This form of response is paternalistic when directed at out-groups, because it combines assumed superiority with potential care taking" (Fiske et al., 2002, p. 896).

Envious prejudice is elicited in response to people placed in quadrant 3 (bottom right) where "high status represents a positive outcome, and competence implies control over it, so these groups are seen as responsible for their position. The lack of warmth imputed to these groups corresponds to perceived competition and hostile intent. When people's own controllable, positive outcomes deprive others, those others feel envy" (Fiske et al., 2002, p. 896). Mixed into envious prejudice is a grudging admiration for their perceived skills.

Contemptuous prejudice is shown in quadrant 4 (bottom left) towards "lowstatus, free-loading groups that are perceived as neither competent nor warm [...] encompassing anger, contempt, disgust, hate and resentment" (Fiske et al., 2002, p. 896).

Admiration and pride are central to quadrant 1) where "some groups elicit unmixed positive regard: pride, admiration, and respect. [...] Admiration is directed towards those with positive outcomes when that does not detract from the self" (Fiske et al., 2002, p. 896).

To belong to the institutional ingroup, therefore, is to be admired and valued, supported and appreciated by one's colleagues - to be liked.
Fiske et al. use the term 'warm'; however the terms 'like' and 'dislike' arise when they are referencing descriptions of:

...perceived subgroups of women (Deaux et al., 1985; Eckes, 1994; Noseworthy \& Lott, 1984; Six \& Eckes, 1991): disliked, dominant, competent, non-traditional women (eg career women, feminists, lesbians, athletes) versus likable, dependent, incompetent, traditional women (eg housewives, sometimes 'chicks'). (Fiske et al, 2002, p. 879)

To be perceived by others as belonging in any of the out-group quadrants can be uncomfortable:

Humans are not biologically or psychologically prepared for being unloved and unwanted. [...] it feels good to feel valued by and validated in a group. Just as important, not having these things feels bad, or worse than bad: incomplete. (Dissanayake, 2000, p. 51)

Things get difficult when the necessary criteria for belonging are mutually in conflict, so if one set of criteria are met, the other set of criteria cannot be met. But they must, somehow and impossibly, be met for membership of the in-group. This is known as the double bind (Bateson et al., 1956; Gibney, 2006). The central tenet of the double bind, in this context, is the tension between being in Fiske's quadrant 2 and likeable, but eliciting paternalistic prejudice and pity, and being in quadrant 3 and disliked and eliciting envious prejudice and grudging admiration. Likeability is weighed against success, but to be included in the institutional in-group a person has to be both successful and liked: two mutually exclusive conditions when applied stereotypically to women.

There are consistent experimental findings of how people assess women in stereotypically male roles (Bohnet, 2016) which indicate that when they have information about performance, people rate successful women as less likeable than men; if no performance information is available, successful women are rated as less competent than men. "Women, thus, are in a double bind that men 
are not. They are perceived as either likeable or competent but not both." Men in counterstereotypical roles are also perceived as less competent but their likeability is not affected.

The double bind is experienced by both women and men in differing ways at all levels of seniority; however, the emphasis in this exploration is gendered. This is not in any way to deny or seek to minimise the incidence of the double bind across the genders in higher education and elsewhere. There is evidence of the double bind in Educated Pass and in Allies in the classroom where young men run the risk of performing their gender wrong by stepping outside what van der Gaag calls the architecture of masculinity (2014).

For a woman to be liked can mean performing one's gender 'correctly' and being nice; however this carries the danger of maintaining and reinforcing paternalistic prejudice and benevolent sexism.

Dardenne et al. (2007) propose that benevolent sexism, in suggesting women's inferiority, can cause women to doubt their abilities. In the recipe Damning with faint praise, an unwilling (ungrateful!) recipient of benevolent sexism says:

[When I was] taking on a new role with considerable responsibility, a senior colleague (already on the management team) welcomed me with the phrase "I'm sure you will do a good job, you are very conscientious". Does he think I am not up to the job?

The recipe goes on to set out how the writer dealt with the faint praise, but for some women:

$$
\begin{aligned}
& \text {...by focusing on positive stereotypical } \\
& \text { characteristics of women [in this } \\
& \text { case conscientiousness], benevolent } \\
& \text { sexism thus implicitly conveys the } \\
& \text { idea of their incompetence and that } \\
& \text { idea coloured women's thoughts } \\
& \text { and affected their autobiographical } \\
& \text { memory. (Dumont et al., 2010, p. 551) }
\end{aligned}
$$

One of the senior women leaders in the University referred to the: ...drip, drip, drip of undermining comments you face as a female academic. It just becomes normal. (From: Leadership perspectives on gender equality)

The issue of competence, perceived as well as internalised, has serious implications within higher education.

Whilst focusing on the gender biases of faculty favouring male students in the sciences in the US, Moss-Racusin et al. (2012) found that female students were less likely to be hired because they were perceived (notably by both male and female faculty members) to be less competent. (From: Gender and the Research Excellence Framework)

And in The current landscape at the University of Edinburgh, Judy Robertson writes:

Teaching is one of the most important aspects of an academic's job, and as such, the University considers student evaluations of teaching (SET) carefully. However, there is research evidence to believe that in general students' evaluations of staff are gender biased with female lecturers receiving harsher ratings (MacNell et al., 2014). Apparently some male students apply the same biases to their peers, as a recent study of biology students found that male students were inclined to overestimate the performance of their male peers (women did not exhibit this bias).

Likeability is also important, not just for the sake of personal and work relationships, but because it has an impact on an individual's career. Unlikeable colleagues do worse in performance evaluations and are deemed less worthy of salary increases and promotions. Bohnet (2016) observes that our biases lead us to react similarly to successful women as to dishonest men, with dislike and a desire to avoid working with them. The result can be that capable individuals are dissuaded - and even prevented - from going for promotion, or move out of academia altogether, unwilling or unable to deal with the issues of likeability. 
This University of Edinburgh student expresses clearly the double bind she finds herself in:

Yet it troubles me that for women, being serious so often is treated as being aggressive, and being cheerful is treated as naivety. l've wasted too much time moulding myself to avoid this, forced into an unfair dichotomy where being taken seriously comes at the expense of being approachable and friendly. (From: Perspectives from students)

Many of the authors in this book explore what it means to be liked or disliked, the causes, and the effects. How do women move beyond the need to be liked when a respected academic can write:

I work hard, I volunteer for things, I try to deliver when I say I will do something. I try to do my job well. I extend myself, then overextend myself. I work at work and I work at home. [...] I sit with my colleagues and think, Please like me. Please like me. Please respect me. At the very least, don't hate me. (Gay, 2014, p. 12)

Some of the EqualBITE authors describe the impossible choices they see as open to them:

\section{Option 1: Be one of the boys}

For many years I tried to fit in. Every time a colleague unthinkingly made a sexist comment I awkwardly laughed and brushed it off. I was telling them that it was OK, that I was cool and one of the guys - not like those other women. In the end this just filled me with repressed rage and self-loathing. I had become part of the very thing I despised. (From: Say something)

\section{Option 2: Be nice}

Women are often expected or forced to provide emotional labour in the form of smiling. How many times have you been asked to smile? At work, at school, in arguments, on the street, in a bar? It's a way to make us provide comfort and aesthetic pleasure even to those we may owe nothing, and a way to ensure women appear unthreatening. (From: Perspectives from students)

\section{Option 3: Be a pain}

There is a risk when you do call out bad behaviour - there is a backlash. I wouldn't be able to call out bad behaviour until I got to this level of seniority. And now I am at this level I feel I have a responsibility to. (From: Leadership perspectives on gender equality)

Being a pain takes its toll:

It can be hard to challenge behaviours that are so embedded that you stop noticing. Small everyday injustices. (From: Leadership perspectives on gender equality)

The double bind can make these choices seem as if they are the only ones available, and make it appear so difficult to open up more positive and constructive options. When issues of stereotyping, prejudice and likeability overlap, many women at all levels of academia can be caught in a double bind where they are, apparently, presented with a stark choice, you can be successful, or be liked. In Kingsley's words you can be good or clever, but you cannot be both.

\section{What next?}

Unpicking the double bind is possible through what Bateson calls a process of demystifying, where the previously hidden process is made visible. Once something is seen, it cannot be unseen. In both Gender balancing your seminar speakers and Leadership perspectives on gender equality, for example, women talk about continuing to put only male names forward for speakers and panels until this is pointed out to them (often by male colleagues). At which point their attitudes and behaviours shift.

In the senior leaders' conversation one of the first people to speak said: "The first step is to recognise that you have a problem." So, having recognised that the problem exists, the demystification process starts, and it becomes possible to work towards everyone being an accepted and valued member of a team irrespective of gender.

Awareness is the first part of Carnes et al's model (see A model for change) and Athena SWAN has already started this process. The 
award brings to the surface and challenges practices that have hitherto been simply part of "that's how things are". The section in this book on career development, for example, reviews approaches to gender balancing recruitment; the gender and language section suggests what individuals can do to uncover their own double binds, challenge and demystify them.

With awareness comes external motivation to make changes, and a wish not to appear biased to one's colleagues. As people practise this, they discover there are benefits to tackling their biases, and the motivation becomes internalised. As the leadership balance shifts from an overrepresentation of men to a more even gender mix, attitudes also shift. Increased levels of women leaders and exposure to a different style of leadership can shift attitudes. For example, in rural India attitudes to women leaders changed significantly once a quota system was introduced for women village leaders (Bohnet, 2016).

Many of the recipe authors in this book give practical advice, based on personal experience, and grounded in the research, to others who are feeling stuck in the double bind of the first three options - to be one of the boys, to be nice or to be a pain. They raise awareness of the unhealthy dynamics of these choices, and open the possibility of moving to a fourth option: to bring the best of oneself to work, and in the process to ask how everyone might be an accepted and valued member of a team, irrespective of gender.

\section{Option 4: Be the best of oneself - good and clever}

In Leadership styles and approaches

in Geosciences a preferred

leadership style is pace-setting.

Pace-setting leadership occurred in the majority of [the] female leadership. [..] I often observe senior female academics setting themselves very high standards.

It is worth noting that these leaders were aware of the dangers of burnout and the need to avoid it:
All interviewees who do implement pace-setting leadership had an awareness that these high expectations needed careful monitoring so that the team is not overwhelmed by the pace setter's demands. (From: Leadership styles and approaches in Geosciences)

The senior leaders in the University championing the conversation are under no illusions themselves about what is involved. Creating an inclusive culture takes effort and courage.

[Where] there is a disparity of gender and power, if it is not called out it sets the culture where that imbalance is OK.

and

Gender inequality is pervasive [in our society] - in my view it's not really changing. The least we can do is work within the institution. But new power structures are fragile: you need to keep your foot on the pedal. (From: Leadership perspectives on gender equality)

Reflection is a continuous part of the process for individuals and for teams and departments, as is recognising one's own unconscious biases (see Challenging bias) and adapting one's style to better work with colleagues. One EqualBITE author noted:

The democratic style of leadership was identified as particularly useful when dealing with senior male colleagues. The challenge of leading older male colleagues was raised by a few of the interviewees who were all extremely comfortable with leading students, postgraduates and peers, but felt less confident with older or dominating (and not always senior) male colleagues. (From: Leadership styles and approaches in Geosciences)

A final word from Leadership perspectives on gender equality:

Once people are openly talking, senior managers set the tone, culture, everyone speaks out. It is about being human. 